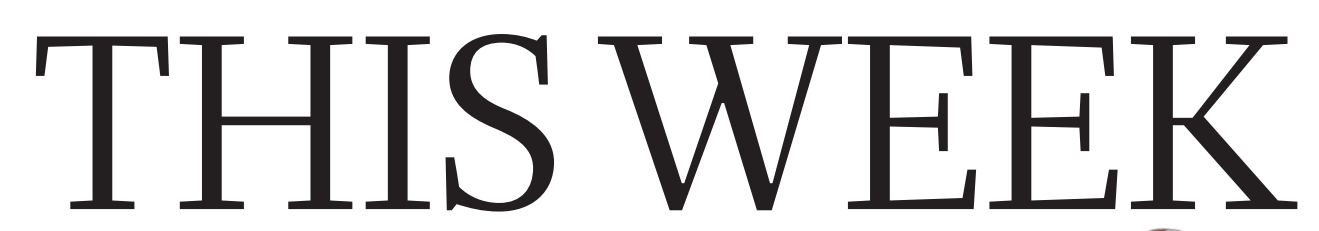

EDITORIALS

EDITORIAL The human genome sequence at ten. What happens now? p.140
WORLD VIEW Lab closure shows we must stand up to drug firms $\mathbf{p . 1 4 1}$
HE'S THE ONE Female

finches stressed by

poor mates p.142

\title{
Letting the bugs out of the bag
}

The public should be properly consulted ahead of any release of experimental insects. But what do they need to know, and whose job is it to ensure the message gets across?

I n the week before Christmas, some 6,000 genetically modified (GM) mosquitoes were deliberately introduced to an uninhabited forest in Malaysia. The move took many local people and international observers by surprise. They had thought that the trial, which aims to investigate how long the modified insects live and how far they can fly, had been postponed.

The mix-up was down to the media confusing the trial with a second planned experiment, due to take place in a populated area later this year. But it adds to a growing sense of unease among some in the field about the way in which the public are consulted and notified about such experiments. The Malaysian trial, developed as an approach to controlling dengue fever by the British biotech company Oxitec, based in Oxford, followed the release of 3.3 million of the firm's GM insects in separate tests in the Cayman Islands in 2009 and 2010.

There is no suggestion that any of the releases was unsafe, or contravened any law. In line with Malaysia's biosafety rules and the Cayman Islands' draft rules, permits were issued after the relevant national authorities performed risk assessments.

But scientists and local people alike have taken issue with the manner in which the public engagement was handled, as well as the choice of the Cayman Islands, where, unlike Malaysia, biosafety considerations are not well developed. Even specialist researchers in the GM mosquito field - hardly a sprawling sector — say that they first heard about Oxitec's experiments in the Cayman Islands only when the company announced the results at an academic conference in November.

If the release of GM organisms is handled badly, it could generate an unnecessary and unhelpful climate of suspicion. One problem is that there is no standard laboratory procedure when it comes to informing the public of such experiments. Moreover, is merely informing them sufficient? Given the farce over the use of GM crops in Europe, early buy-in and support from local communities would be a good way to deflect unfounded fears that could surface in the future, particularly given that early findings are promising. (Oxitec says the release of the GM mosquitoes in the Cayman Islands study successfully reduced the wild dengue-carrying population by about $80 \%$.) But researchers who work on GM insects say that they are unsure how much public engagement is enough and who has responsibility for it.

Transparency is essential. The Malaysian authorities went to some lengths to inform people that the trials were going ahead, holding open forums and briefing the media, which gave the experiments wide coverage. The resulting discussion highlighted concerns. It also seeded an appetite for more information, which seems to have been responsible for the subsequent confusion over the trial's timing. By contrast, efforts by the Cayman Island authorities seem to have amounted to not much more than producing little-reported leaflets and a video, posted on YouTube and broadcast on television, which failed to say that the mosquitoes were genetically modified - the main concern of critics.
Researchers, both in the public and private sector, should do more to ensure that the relevant authorities make the relevant facts available, or do so themselves. It is they, not the authorities, after all, that will probably be the focus of protests and complaints if public engagement is handled badly. With this in mind, scientists at the University of California, Irvine,
"If the release of GM organisms is handled badly, it could generate an unnecessary and unhelpful climate of suspicion." have developed and published a detailed and ambitious framework to engage the public in global-health initiatives (J. V. Lavery et al. Trends Parasitol. 26, 279-283;2010) - heavily based on their own experiences with GM mosquito research in Mexico.

In the absence of guidelines to help researchers to deal with local communities, the authors produced 12 of their own, which include rigorous site selection, to ensure that the purpose and goals of the research are made clear, and the use of focus groups and citizen councils to probe local opinions and to decide whether informed consent is necessary. Although many of the issues are common to such research, the decisions must be taken on a siteby-site basis, they say. The World Health Organization is also drawing up guidelines, which it says will help scientists to assess the social and cultural issues relating to their work.

Oxitec acknowledges that there are lessons to learn from its experiences. Best placed to judge the results of this are the people of Brazil, the planned site of the company's next experiment.

So far, GM mosquitoes and other insects have largely flown beneath the radar. That will change sooner or later. It is surely better that the scientists involved bring them to the public's attention, rather than have that attention thrust upon them by others.

\section{A fair share}

\section{The Hungarian government needs to up its stake in the nation's scientific future.}

$\mathrm{F}$ or almost 20 years, the Collegium Budapest has stood as a symbol of a new era of science in central and eastern Europe. Some 700 scholars from 40 countries have spent time in its rarefied intellectual atmosphere - an esteemed institute for advanced study - where, free from teaching and administrative burdens, they have produced hundreds of papers and books in fields ranging from economics to political sciences, theoretical biology and the humanities. Given its widely recognized success, why does the collegium now face threats to its survival? 